\title{
Isolation and characterization of a novel plasma membrane protein, osteoblast induction factor (obif), associated with osteoblast differentiation
}

\author{
Takashi Kanamoto ${ }^{1,2}$, Koji Mizuhashi1 ${ }^{1}$, Koji Terada1 ${ }^{1}$ Takashi Minami ${ }^{3}$, \\ Hideki Yoshikawa ${ }^{2}$ and Takahisa Furukawa*1
}

Address: ${ }^{1}$ Department of Developmental Biology, Osaka Bioscience Institute, 6-2-4 Furuedai, Suita, Osaka 565-0874, Japan, ${ }^{2}$ Department of Orthopedic Surgery, Graduate School of Medicine, Osaka University, Osaka 565-0871, Japan and ${ }^{3}$ Department of Molecular and Vascular Medicine, The Research Center for Advanced Science and Technology, University of Tokyo, Tokyo 153-8904, Japan

Email: Takashi Kanamoto - kanamoto@obi.or.jp; Koji Mizuhashi - mizuhashi@obi.or.jp; Koji Terada - terada@obi.or.jp;

Takashi Minami - minami@lsbm.org; Hideki Yoshikawa - yhideki@ort.med.osaka-u.ac.jp; Takahisa Furukawa* - furukawa@obi.or.jp

* Corresponding author

Published: 21 December 2009

BMC Developmental Biology 2009, 9:70 doi:10.1 I86/I47I-2I3X-9-70

This article is available from: http://www.biomedcentral.com/I47I-2/3X/9/70

(C) 2009 Kanamoto et al; licensee BioMed Central Ltd.

This is an Open Access article distributed under the terms of the Creative Commons Attribution License (http://creativecommons.org/licenses/by/2.0), which permits unrestricted use, distribution, and reproduction in any medium, provided the original work is properly cited.
Received: 4 May 2009

Accepted: 21 December 2009

\begin{abstract}
Background: While several cell types are known to contribute to bone formation, the major player is a common bone matrix-secreting cell type, the osteoblast. Chondrocytes, which plays critical roles at several stages of endochondral ossification, and osteoblasts are derived from common precursors, and both intrinsic cues and signals from extrinsic cues play critical roles in the lineage decision of these cell types. Several studies have shown that cell fate commitment within the osteoblast lineage requires sequential, stage-specific signaling to promote osteoblastic differentiation programs. In osteoblastic differentiation, the functional mechanisms of transcriptional regulators have been well elucidated, however the exact roles of extrinsic molecules in osteoblastic differentiation are less clear.

Results: We identify a novel gene, obif (osteoblast induction factor), encoding a transmembrane protein that is predominantly expressed in osteoblasts. During mouse development, obif is initially observed in the limb bud in a complementary pattern to Sox 9 expression. Later in development, obif is highly expressed in osteoblasts at the stage of endochondral ossification. In cell line models, obif is up-regulated during osteoblastic differentiation. Exogenous obif expression stimulates osteoblastic differentiation and obif knockdown inhibits osteoblastic differentiation in preosteblastic MC3T3-EI cells. In addition, the extracellular domain of obif protein exhibits functions similar to the full-length obif protein in induction of MC3T3-EI differentiation.
\end{abstract}

Conclusions: Our results suggest that obif plays a role in osteoblastic differentiation by acting as a ligand. 


\section{Background}

The skeleton is a multifunctional system with physiological roles in providing a rigid framework and support, acting as the primary storage site for mineral salts, and functioning in hematopoiesis. While several cell types are known to contribute to bone formation, the major player is a common bone matrix-secreting cell type, the osteoblast.

Chondrocytes, which play critical roles at several stages of endochondral ossification, and osteoblasts are derived from common precursors, and both intrinsic cues and signals from extrinsic cues play critical roles in the lineage decision of these cell types [1-3]. The targeted mutation of Runx2 or Osterix, transcription regulators highly expressed in osteoblast progenitors, result in the lack of mature osteoblasts, demonstrating that these factors are essential for osteoblastogenesis [4-7]. Several studies have shown that cell fate commitment within the osteoblast lineage requires sequential, stage-specific, Ihh and canonical Wnt/ $\beta$-catenin signaling to promote osteoblastic, and also to block chondrogenic, differentiation programs [8-11]. Another recent report shows that the inhibitory effect of Soxy on osteoblastic and chondrocyte maturation via repression of Runx2 function is an essential mechanism for osteochondroprogenitor cell fate determination [12].

Most bones are formed by endochondral ossification in which mesenchymal condensations differentiate into chondrocytes, forming a cartilaginous template prefiguring the future skeletal elements. The perichondrium and perioseum are generated around the nascent cartilage, and cells surrounding the zone of hypertrophic chondrocytes begin to differentiate into osteoblasts. Sox9 is expressed in all chondroprogenitors and chondrocytes except hypertrophic chondrocytes, and is required for the sequential steps of chondrogenesis before and after mesenchymal condensations $[13,14]$.

Thus, in osteoblastic differentiation, the functional mechanisms of transcriptional regulators have been well elucidated, however the exact roles of extrinsic molecules in osteoblastic differentiation are less clear. In our microarray screening aiming to identify novel molecular pathways in chondrocyte differentiation, we identified a novel gene encoding a transmembrane protein, which is predominantly expressed in osteoblasts during mouse development. We named this gene obif (osteoblast induction factor) and performed functional analyses using cell culture models.

We found that obif overexpression in the preosteoblastic MC3T3-E1 cells induces differentiation and maturation of osteoblasts. Knockdown of obif suppresses osteoblastic differentiation of MC3T3-E1 cells. We also present data demonstrating that the extracellular domains of both mouse and human obif proteins augment osteoblastic differentiation-induction activity, suggesting that obif acts in a ligand-like manner. Together, our results suggest that obif is involved in the differentiation of osteoblasts through intercellular interaction during development.

\section{Results}

Identification and intracellular localization of obif protein With the aim of identifying novel molecules involved in chondrocyte differentiation, we performed a microarray screening using a mouse chondroprogenitor cell line, ATDC5 (Figure 1A). We extracted total RNA at day 0 (the confluence stage), day 9 (the cartilage nodule formation stage), and day 37 (the cellular hypertrophy and calcification stage). With the gene expression profile analysis, we identified 131 probe sets that showed more than a threefold change in expression level at day 9 or day 37 relative to day 0 . From among these genes, we selected 25 genes that have not as yet been known to be associated with chondrogenesis and osteoblastogenesis, and further investigated their expression patterns. We found one gene that shows an expression pattern predominantly in the skeletal systems of mouse embryos and up-regulation upon differentiation in ATDC5 cells. On the basis of our functional assay, we named this gene obif (osteoblast induction factor) (GenBank TPA \#BC025600) (Figure 1B) which is the same gene with transmembrane protein 119 (tmem119).

The deduced amino acid sequence of mouse obif contains a signal sequence, a single transmembrane domain, and a glutamic acid-rich region. This gene is conserved among species from chicken to human (Figure 1C and Additional file 1). We also isolated a human OBIF cDNA from commercially available human fetal brain RNA by RT-PCR. The genomes of zebra fish and Xenopus tropicalis also contain sequences that are homologous to mouse obif (data not shown). We then examined the subcellular localization of obif. Using a retrovirus vector, we overexpressed a FLAG-tagged obif in various cell lines. To confirm the obif expression, we performed Western blot analysis using anti-FLAG M2 antibody and the antibody that we raised against obif (Figure 1D). With both of these antibodies, we detected a strong band of approximately $37 \mathrm{kD}$, a weak band of approximately $44 \mathrm{kD}$, and broad bands of $50-75$ $\mathrm{kD}$ in all cell lines in which obif was overexpressed (Figure 1D). Using the on-line predictor method NetOGlyc 3.1 [15], we found several potential O-glycosylation sites between the signal sequence and transmembrane domain of obif (Additional file 1). This observation strongly suggests that obif is a type Ia transmembrane protein in which the N-terminal region is frequently modified posttranscriptionally. Next, we examined the intracellular 
A

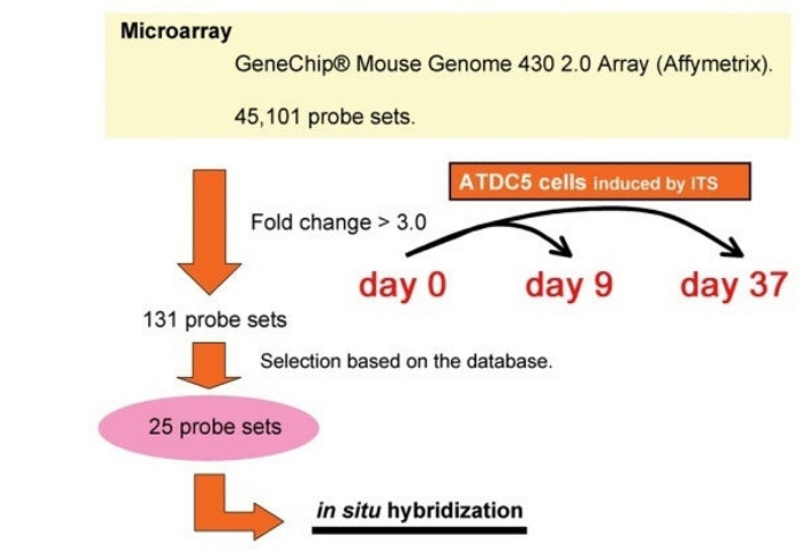

C

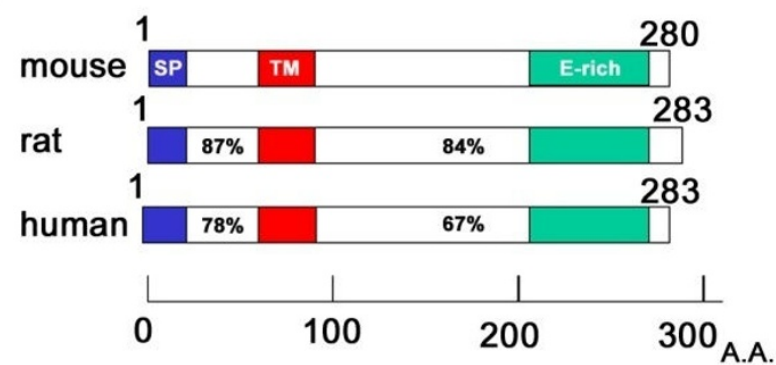

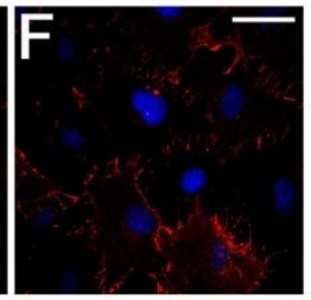
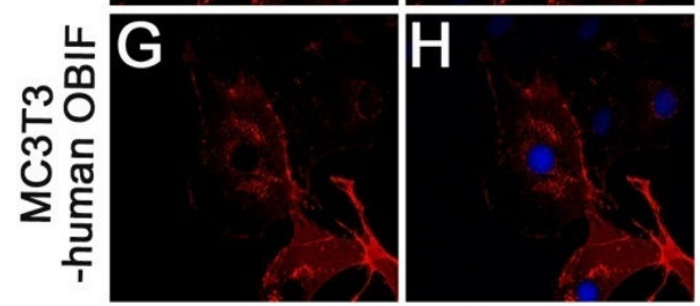

B

\begin{tabular}{|c|c|c|c|}
\hline \multirow[b]{2}{*}{ Gene } & \multirow[b]{2}{*}{ Affymetrix description } & \multicolumn{2}{|c|}{ Fold change $\left(\log _{2}\right)$} \\
\hline & & day $9 /$ day 0 & day $37 /$ day 0 \\
\hline \multirow[t]{4}{*}{ sox 6} & AJ010605.1 & 1.3 & 1.8 \\
\hline & AV281802 & 1.5 & 2.1 \\
\hline & BB257593 & 1.2 & 1.8 \\
\hline & D61689.1 & 1.2 & 1.5 \\
\hline Sox 9 & BI077717 & 0.8 & 1.0 \\
\hline collagen 2 a1 & NM_031163.1 & 3.3 & 3.4 \\
\hline collagen $10 \mathrm{a} 1$ & NM_009925.1 & 4.6 & 6.7 \\
\hline \multirow[t]{3}{*}{ collagen 11 a2 } & AV242706 & 4.4 & 4.8 \\
\hline & NM_007729.1 & 2.4 & 2.0 \\
\hline & BB836814 & 2.2 & 2.0 \\
\hline aggrecan1 & BB658835 & 4.8 & 5.9 \\
\hline BC025600 (obif) & BC025600.1 & 4.9 & 6.3 \\
\hline
\end{tabular}

D
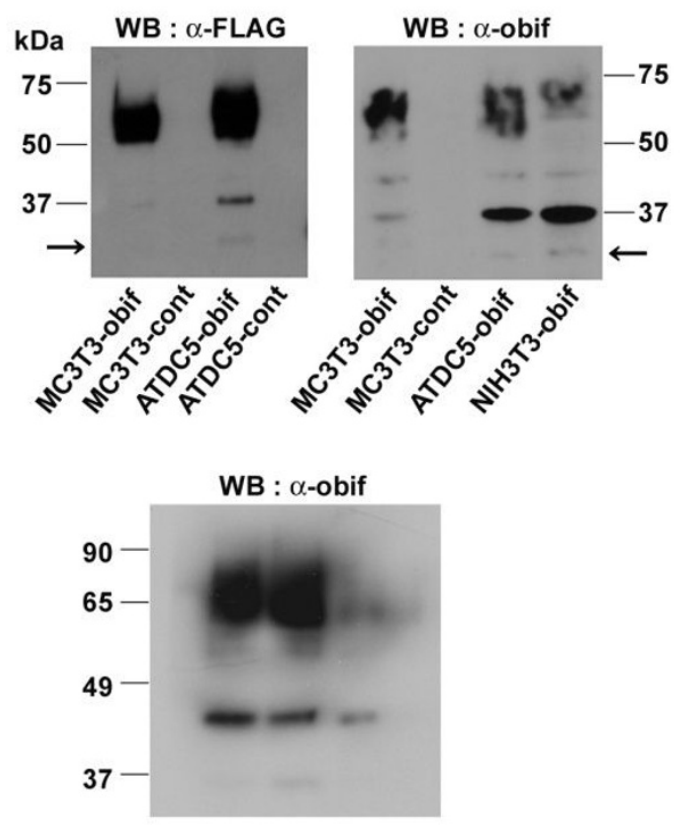

WB : $\beta$-actin

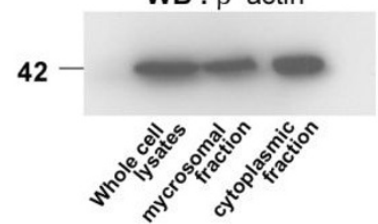

Figure I (see legend on next page) 
Figure I (see previous page)

Identification of a novel plasma membrane protein, obif, and its subcellular localization. (A) The strategy of microarray-based screening to identify up-regulated genes in chondrocyte differentiations of ATDC5 cell line. (B) Fold changes of representative chondrocyte markers (black) and obif (red) transcripts which are up-regulated in the microarray analysis. (C) Schematic diagram of obif protein structure. The percent sequence identities of each region are shown: SP, signal peptide; TM, transmembrane domain; E-rich, glutamic acid-rich domain. Numbers represent amino acid residues. (D) Detection of FLAGtagged obif protein. Whole cell lysates of MC3T3-obif, MC3T3-cont, ATDC5-obif, ATDC5-cont, and NIH3T3-obif were electrophoresed by SDS-PAGE. Immunoblots were probed with anti-FLAG M2 antibody or anti-obif antibody. Arrows represent the molecular size of obif protein predicted from its amino acid sequences $(29.4 \mathrm{kDa})$. $(\mathrm{E}-\mathrm{H})$ Confocal analysis of overexpressed mouse and human obif in MC3T3-EI cells. Cells expressing FLAG-tagged mouse obif were stained with anti-obif antibody (red) (E, F). Cells expressing FLAG-tagged human OBIF were stained with anti-FLAG M2 antibody (red) (G, H). Nuclei were stained with DAPI (blue). Scale bar $=50 \mu \mathrm{m}$. (I) Subcellular localization of obif protein. Subcellular fractions of ST2 cells expressing exogenous mouse obif were analyzed by Western blotting. Immunoblots were probed with an anti-obif antibody to localize obif (top) and with an antibody against $\beta$-actin, an abundant cytoplasmic protein (bottom).

localization of obif using MC3T3-E1 cells stably overexpressing mouse obif (MC3T3-obif) or human OBIF (MC3T3-OBIF) by immunostaining (Figures 1E-H). Obif/ OBIF are mainly localized to the plasma membrane. This observation is coincident with the result of Western blot analysis on the subcellular fractionated samples (Figure 1I), in which the microsomal fraction contained an abundant amount of obif compared with the cytoplasmic fraction.

\section{Obif transcript is expressed in osteoblast-lineage cells}

Early mouse embryos were examined for obif transcript expression by whole mount in situ hybridization (Figures $2 \mathrm{~A}$ and $2 \mathrm{~B}$ ). No clear hybridization signal was detected at E8.5 (data not shown). At E9.5, the signal was seen in the whole limb buds (Figure 2A). At E12.5, the stage the cartilage primordiums were formed in the limb buds, obif transcripts were observed in the areas between these primordiums (Figure 2B).

We then compared the expression of obif with that of the chondrocytic marker Sox9 (Figures 2C-P). In the forelimb bud, obif is expressed in a broad region at E9.5 (Figure 2A). At E10.5 and E11.5, the signal is down-regulated in the proximal region where mesenchymal cells condense and differentiate into chondrocytes, as evidenced by the onset of Sox9 expression (Figures 2C, D, G, and 2H). At E12.5 and E13.5, while Sox9 shows a prominent signal in future digit regions, the expression of obif is most abundant in the interdigital mesenchyme (Figures 2E, F, I, and $2 \mathrm{~J})$. As in developing limb buds, obif expression is complementary to that of Sox9 in other tissues (Figures 2D, H, K$\mathrm{P})$. For instance, obif is expressed in cells between the condensations that form the future ribs at E11.5 (Figure 2D) and in the osteogenic mesenchyme surrounding Meckel's cartilage at E12.5 (Figures 2K-M). However, we could not detect obif transcripts in the chondrocyte-lineage cells such as the cartilage condensation and Meckel's cartilage where Sox9 is expressed (Figures 2C-P).
To investigate the obif transcript expression at later embryonic stages, we performed section in situ hybridization with several markers pertaining to endochondral ossification (Figures 2Q-Y). Collagen 1(Col.1) and osteocalcin (ocn) are markers for mature osteoblasts. Osteopontin (opn) is a marker for both terminally differentiated chondrocytes and osteoblasts, and collagen 10 (col.10) is a marker for hypertrophic chondrocytes. Interestingly, the expression of obif was observed in the osteoblasts. In E14.5 humerus, obif transcripts were detected in the perichondrium of the hypertrophic chondrocyte region where collagen 1 is expressed, but were absent from more centrally located chondrocytic cells (Figures 2Q and 2R). At E15.5, when ocn is not yet significantly expressed, obif is detected both in the prospective bone collar region marked with collagen 1 and in the developing bone trabeculae marked with opn (Figures 2S-V). At E17.5, obif expression overlaps with ocn but not with collagen 10 (Figures 2W-Y).

Next, we examined the expression of obif and Runx2 in various tissues of 4 week-old mice by Northern blot analysis (Figure 2Z). A $2.1 \mathrm{~kb}$ band was detected in the tissues containing osteoblasts (calvaria, long bones) and other tissues such as the brain and lung. The calvaria band was significantly stronger as compared with that of the brain or lung. High levels of obif expression at embryonic stages followed by decreased expression of obif at early postnatal stages suggest that obif works in both embryonic skeletal development and postnatal differentiation. During postnatal development, expression in calvaria and long bones decreases whereas Runx2 expression is comparably maintained (Figure 2AA), suggesting that obif does not have an important role in mature adult tissues.

\section{Obif expression is up-regulated during osteoblastic differentiation in cell line models}

Several cell lines derived from mesenchymal tissues have been widely used to recapitulate in vivo cellular differentiation [16-20]. We used preosteoblastic MC3T3-E1 cells, 

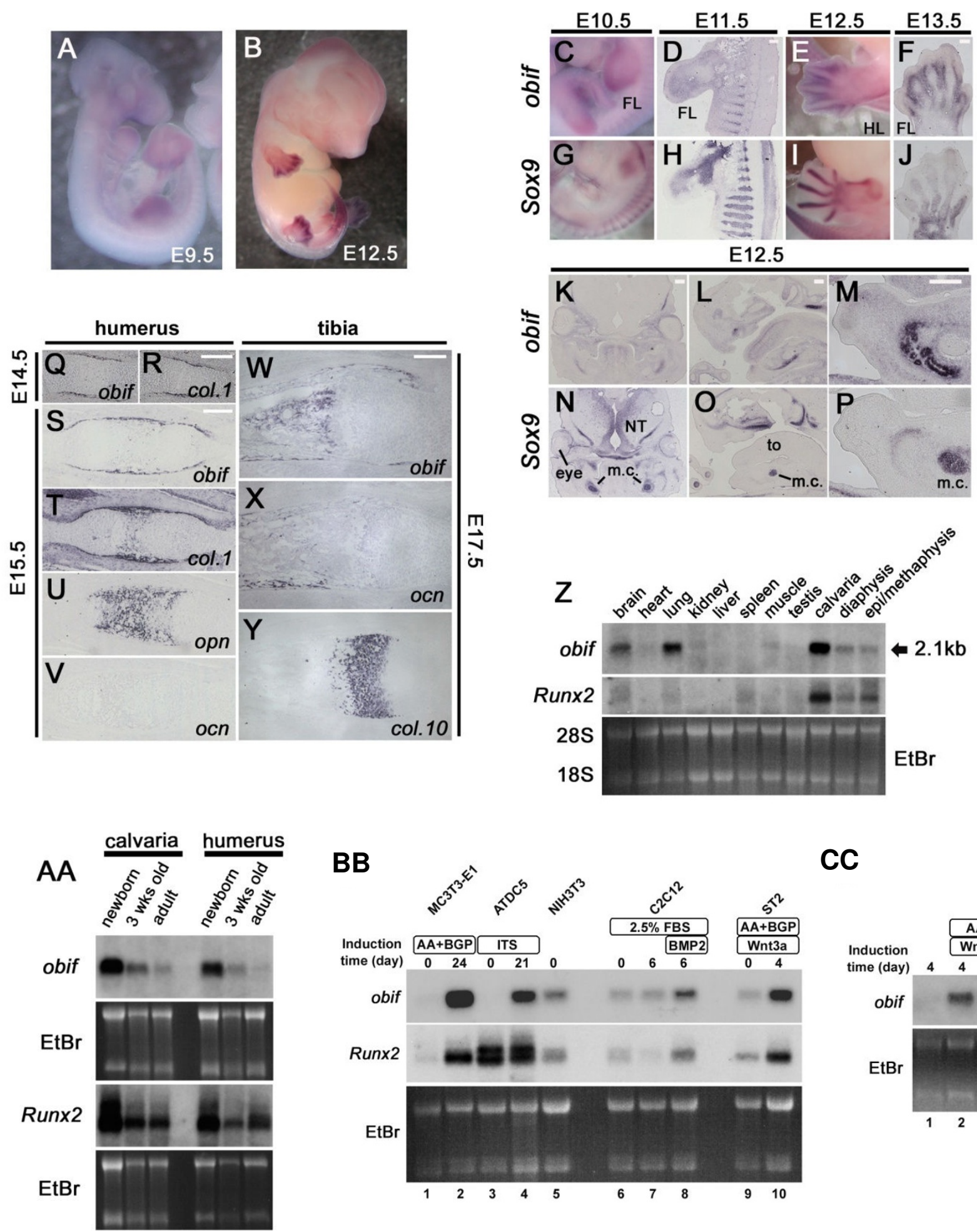

BB

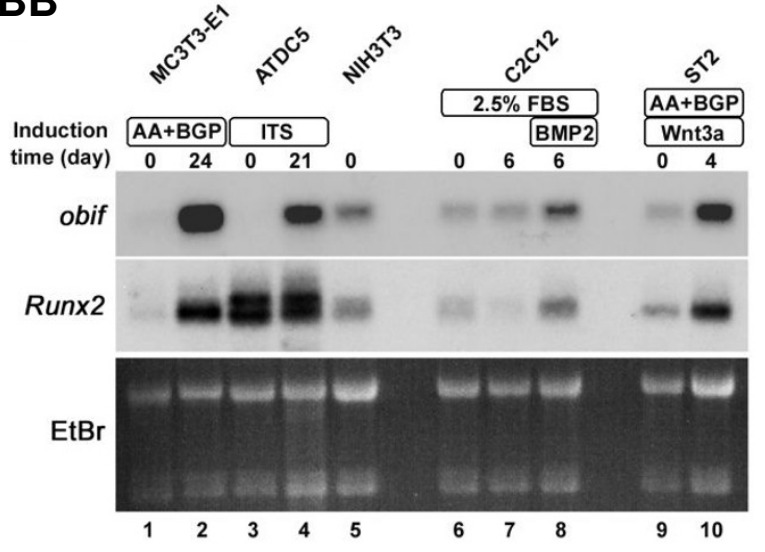

CC

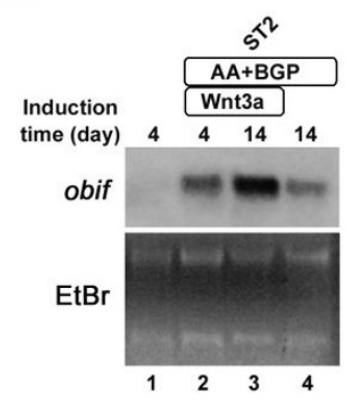

Figure 2 (see legend on next page) 
Figure 2 (see previous page)

Predominant expression of obif transcript in osteoblast-lineage cells. (A, B) Expressions of obif in mouse embryos examined by whole mount in situ hybridization. (C-P) In situ hybridization analysis of mouse obif and Sox9 in the developing mouse limb, rib, and mandible. Obif expression was complementary to that of Sox9 in the developing limb bud (C-J), rib (D, H) and mandible (K-P). FL, forelimb; HL, hindlimb; NT, neural tube; to, tongue; m.c., Meckel's cartilage. Scale bars $=200 \mu \mathrm{m}$. (QY) Section in situ hybridization of mouse obif in endochondral ossification. At El4.5 obif transcripts were detected in the perichondrium but were absent from more centrally located chondrocytic cells (Q, R). In EI5.5 humerus and EI7.5 tibia, obif expression was found in cells associated with bone trabeculae and in cells associated with the formation of bone collars (S-Y). Scale bars $=200 \mu \mathrm{m}$. (Z) Northern blot analysis of obif and Runx2 expression in 4 week-old mouse tissues. The arrow corresponds to a 2.I kb obif transcript. (AA) Northern blot analysis of obif and Runx2 expression in the calvaria and humeri harvested from newborn, 3 week-old, and adult mice. (BB, CC) Northern blot analysis of obif and Runx2 transcripts in cell differentiation models of osteoblasts and chondrocytes. Total RNAs, extracted from MC3T3-EI cells (BB: lane I, undifferentiated cells; lane 2, cells cultured in differentiation medium for 24 days), ATDC5 cells (BB: lane 3, undifferentiated cells; lane 4, cells cultured in differentiation medium for $2 \mathrm{I}$ days), NIH3T3 cells (BB, lane 5), C2CI 2 cells (BB: lane 6, undifferentiated cells; lane 7, cells cultured in myogenic differentiation medium for 6 days; lane 8, cells cultured in osteoblastic differentiation medium for 6 days), and ST2 cells (BB: lane 9, cells cultured in growth medium; lane 10, cells cultured in medium supplemented with Wnt3a and ascorbic acid for 4 days; and CC: lane I, cells cultured in growth medium for 4 days; lane 2, cells cultured in medium with Wnt3a and ascorbic acid for 4 days; lane 3, cells cultured in medium with Wnt3a and ascorbic acid for 14 days; lane 4 , cells cultured in medium with ascorbic acid for 14 days) were used for Northern blot analysis.

myogenic C2C12 cells, and stromal ST2 cells as osteoblast differentiation models, and chondrogenic ATDC5 cells as a chondrocyte differentiation model. Initially, the endogenous obif in these cells was examined in comparison with Runx2 by Northern blot analysis (Figure 2BB). In undifferentiated MC3T3-E1 cells only a faint signal was detected, however, upon induction by ascorbic acid (AA) and $\beta$ glycerophosphate (BGP), obif transcripts dramatically increased (Figure 2BB: lanes 1 and 2). Similarly, although ATDC5 cells express almost no obif transcript in an undifferentiated state, obif expression is markedly up-regulated during differentiation induced by ITS (insulin/transferrin/ sodium selenite) (Figure 2BB: lanes 3 and 4). NIH3T3 cells express a low amount of obif and Runx2 transcripts (Figure 2BB: lane 5). In $\mathrm{C} 2 \mathrm{C} 12$ cells, obif expression increased during osteoblastic differentiation induced by BMP2 (Figure 2BB: lanes 6-8). In ST2 cells, obif expression increased during differentiation induced by ascorbic acid or Wnt 3a (Figure 2BB: lanes 9 and 10, and Figure 2CC: lanes 1-4).

\section{Endogenous obif protein is expressed in osteoblast-lineage cells}

In order to investigate the localization of endogenous obif protein, we immunostained sections of embryonic forelimb and humerus using the anti-obif antibody (Figures 3A-E). Signals were observed in the perichondrium of the hypertrophic chondrocyte region, peripheral layers of the endochondral skeletal elements, and cells associated bone trabeculae including both the spindle-shaped osteoblasts and the cuboidal-shaped osteoblasts. In addition, we observed that obif appears to be expressed in the plasma membrane of osteoblasts (Figures 3C and 3E). To verify the expression of obif protein in osteoblast-lineage cells, we performed double staining of the developing limb using the obif antibody with other osteoblastic markers such as alkaline-phosphatase (ALP) and collagen 1 (Figures 3F-I). At late embryonic stages, co-localization of obif with ALP or with collagen type I was observed in the femur (Figures 3F and 3G) and hindlimb (Figures $3 \mathrm{H}$ and 3I).

Next, we examined obif protein expression in primary cultures of fetal mouse calvaria (Figures 3J-O). When calvarial cells were sparsely cultured, no obvious obif signals were observed (Figures 3J and 3M). On the other hand, when densely cultured cells were stimulated with osteoblastic differentiation medium, strong obif expression was detected (Figures $3 \mathrm{~K}$ and $3 \mathrm{~N}$ ). By western blot analysis using primary culture cells and MC3T3-E1 cells, the elevation of the protein level was observed during calvarial cell maturation (Figure 3P).

\section{The role of obif in osteoblastogenesis}

We then performed cell differentiation analysis using the retrovirus vector. For the overexpression study, cells were infected with retroviruses expressing both obif and GFP through IRES or expressing GFP only as a control. The infection efficiency was monitored by GFP expression (Additional file 2A, D, G, and 2J). Obif expression was confirmed by immunocytochemistry (Additional file 2C and 2I) and Western blot analysis using anti-obif antibody (Figure 1D). These results show that cultured cells can be infected efficiently (>95\%) with retroviruses. These infected cells express GFP and/or obif protein even after extensive passaging. For gene knockdown, we made retroviruses expressing short hairpin RNAs (shRNAs) against obif. First, we designed three different siRNAs (siRNA-1, 

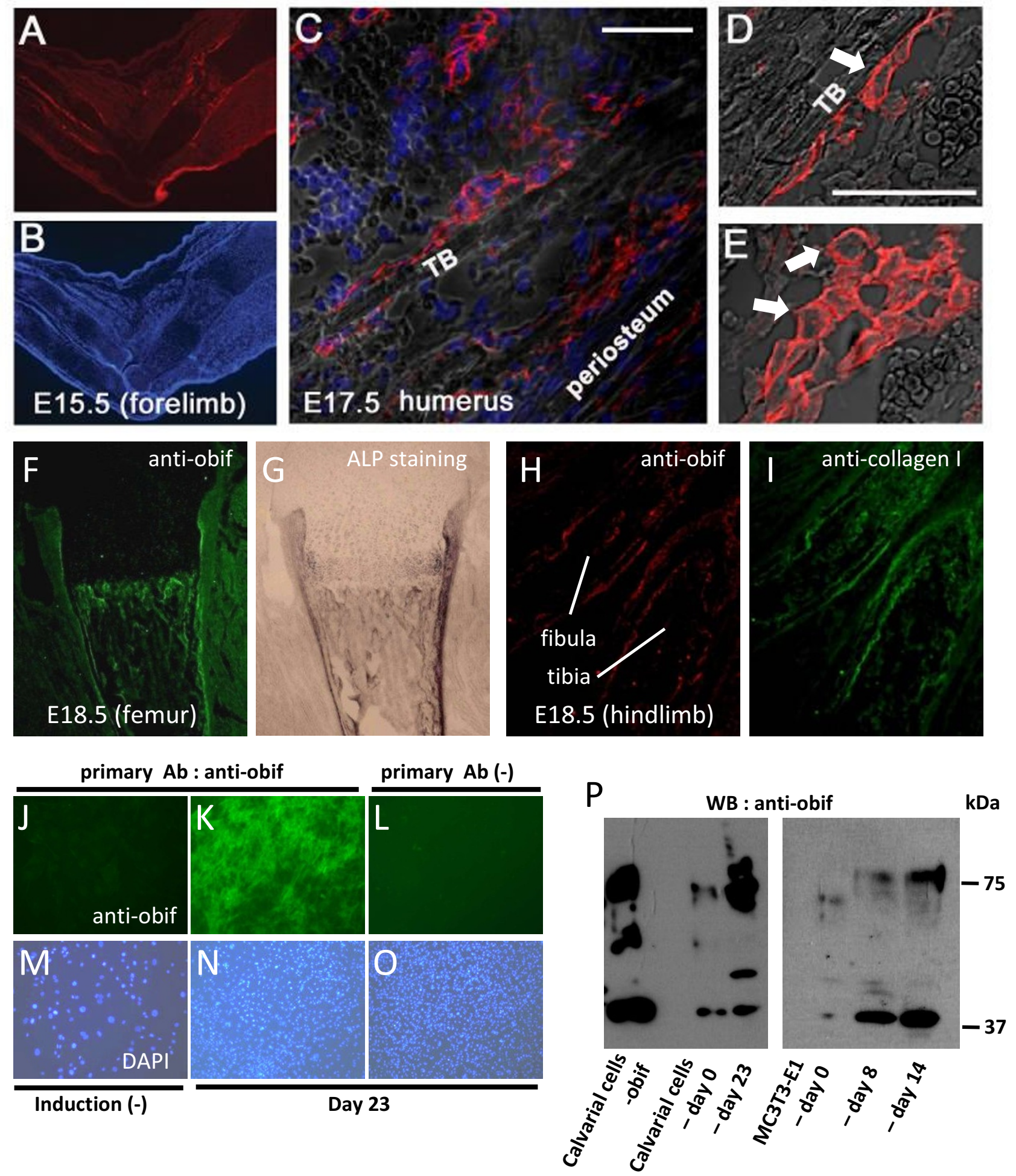

Figure 3 (see legend on next page)
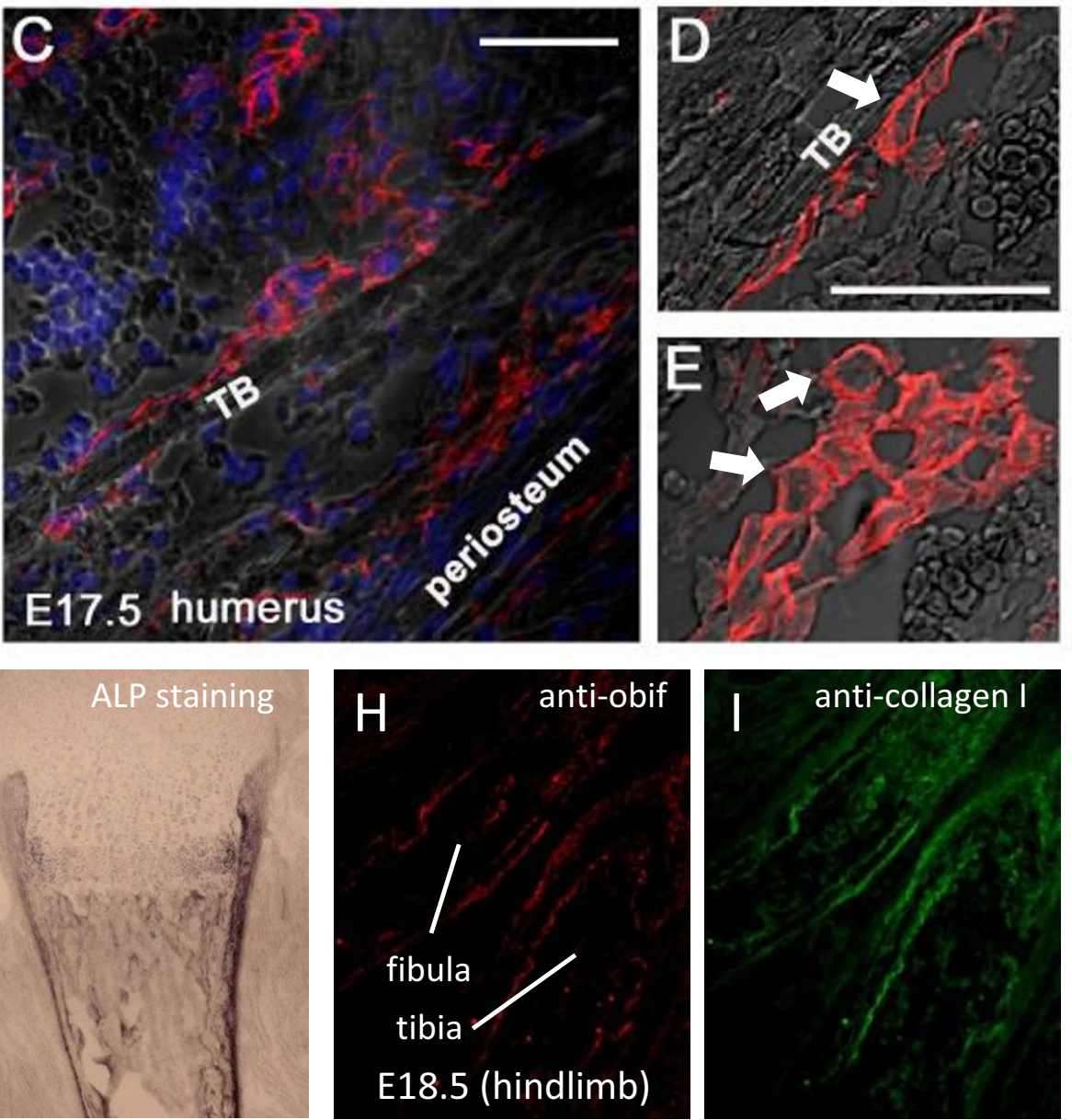

E18.5 (hindlimb) 
Figure 3 (see previous page)

Predominant expression of obif protein in osteoblast-lineage cells. (A-E) Immunostaining of developing limbs using anti-obif antibody. Sections of limbs were stained with anti-obif antibody (red) and nuclei were stained with DAPI (blue). EI5.5 forelimb sections (A, B). Scale bars $=200 \mu \mathrm{m}$. El7.5 humerus sections (C). Obif was expressed in spindle-shaped osteoblasts lining trabecular bone surfaces and in cuboidal-shaped osteoblasts. Scale bars $=50 \mu \mathrm{m}$. Higher magnification of EI7.5 humerus sections shows that obif is localized to the plasma membrane $(D, E)$. White arrows indicate typical cells that show the transmembrane pattern. (F, G) E I8.5 femur section was first stained with anti-obif antibody (green) and then stained for ALP. (H, I) E I8.5 hindlimb section was double-stained with anti-obif antibody (red) and anti-collagen I antibody (green). (J-O) Primary calvarial cells cultured in 12 -well plates were immunostained with anti-obif antibody (J-L) and DAPI (M-O). Sparsely cultured cells $(\mathrm{J}, \mathrm{M})$. Densely cultured cells were incubated in presence of ascorbic acid for 23 days and used for analysis (K-O). L \& $O$ are negative controls. (P) Detection of endogenous obif protein. Whole cell lysates of calvarial cells-obif (stably infected), calvarial cells-day 0 (not stimulated), calvarial cells-day 23 (stimulated for 23 days), MC3T3-EI cells-day 0 (not stimulated), MC3T3-EI cells-day 8 (stimulated for 8 days), and MC3T3-EI cells-day 14 (stimulated for 14 days) were electrophoresed by SDS-PAGE. Immunoblots were probed with the anti-obif antibody. Calvarial cells-obif is a positive control.

siRNA-2, and siRNA-3) and examined their knockdown effects (Additional file 3). MC3T3-obif cells and ATDC5obif cells were transfected with siRNA-1, siRNA-2, siRNA3, or control siRNA and analyzed by Western blotting. Non-transfected MC3T3-obif cells and ATDC5-obif cells were also electrophoresed. All of the siRNAs against obif showed strong knockdown effects (Additional file 3). Next, we made retroviral constructs overlapping the effective siRNA sequences, a control shRNA (sh-cont), sh292 which sequence overlaps siRNA-1 and siRNA-2 sequences, and sh301 which sequence overlaps siRNA-3 sequence. When infected, MC3T3-obif cells with sh292 retroviruses showed a strong knockdown effect and those with sh301 retroviruses showed a comparatively weak knockdown effect (Additional file 3). Using these retroviruses, we established cells stably expressing these shRNAs and performed knockdown studies.

Initially, we examined the effect of obif overexpression on cell growth (Figures $4 \mathrm{~A}$ and $4 \mathrm{~B}$ ). The proliferation rate decreased somewhat in MC3T3-obif cells compared with MC3T3-control (MC3T3-cont) cells (Figure 4A). The same effects of exogenous obif were observed in other cell lines, ATDC5, ST2, and C2C12 (data not shown). On the other hand, MC3T3-sh292 and -sh301 cells showed almost the same cell growth as cells infected with control retrovirus (MC3T3-sh-cont) (Figure 4B). This result indicates that effect of obif on cell differentiation described below is not mainly due to the effects on cell growth.

Next, we investigated the relationship between obif expression and osteoblast differentiation. We first examined an early stage osteoblastic marker, ALP activity. The retrovirally infected cells were cultured in osteoblast differentiation media and harvested at the indicated time points (Figures 4C and 4D). While ALP activity increased in a time-dependent manner both in MC3T3-obif and -cont cells, MC3T3-obif cells showed a significantly higher ALP activity than the MC3T3-cont cells at all points examined
(Figure 4C). In contrast, the reduction of obif expression caused a significant decrease of ALP activity at all time points examined (Figure 4D). Second, we cultured MC3T3-E1 cells in the differentiation-induction medium until mineralized nodules could be observed. Mineralization was visualized by Alizarin Red staining and quantified by a biochemical assay for calcium. A significantly higher degree of mineralization was obtained in MC3T3obif cells than in MC3T3-cont cells (Figures 4E-H). A quantitative analysis of calcium by extraction of the calcified mineral also showed a higher calcium content in MC3T3-obif cells (Figure 4M). In contrast, decreased mineralization was observed in MC3T3-sh292 cells and MC3T3-sh301 cells as compared with MC3T3-sh-cont cells (Figures $4 \mathrm{I}-\mathrm{L}$ and $4 \mathrm{~N}$ ). In addition, we examined the effect of human $O B I F$ on mineralization and confirmed that it also promoted mineralization (Additional file 4).

Aiming to investigate the effect of obif at the molecular level, we examined the expression of osteoblast lineageassociated genes by Northern blot analysis (Figures 5AD). In obif overexpression experiments, the mRNA levels of the osteoblastic differentiation markers increased in MC3T3-obif cells compared with those in MC3T3-cont cells. In particular, the elevations of $b s p$ and ocn mRNA levels were prominent (Figure 5A). In knockdown experiments, obif transcripts were almost completely abolished in MC3T3-sh292 cells and partially ablated in MC3T3sh301 cells (Figures 5B-D). As early and essential osteoblastic markers, we first examined Runx2 and Osx mRNA levels (Figure 5B). At day 14, Osx transcripts decreased in obif knocked down cells whereas Runx2 transcripts were not influenced by obif levels. At day 28, Runx2 was downregulated in MC3T3-sh292 cells while we could detect only faint evidence of obif mRNA. To investigate the relationship between Runx2 and obif, we established Runx2 knocked down MC3T3-E1 cells (MC3T3-shRunx2) and compared with obif knocked down cells (Figure 5C). In MC3T3-shRunx2 cells, obif was down-regulated whereas 
A

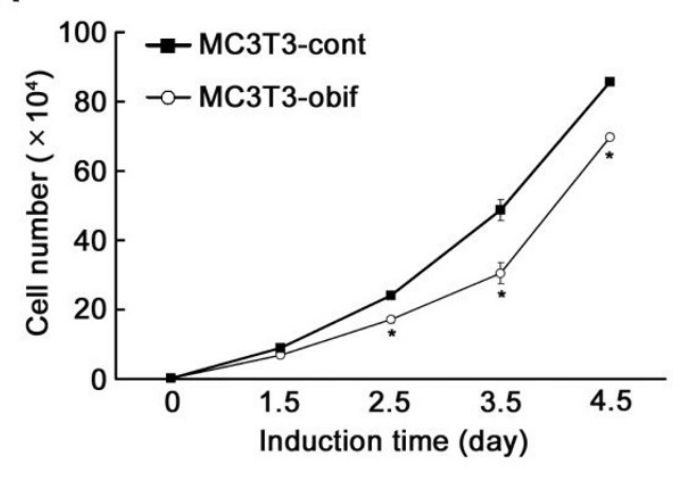

C
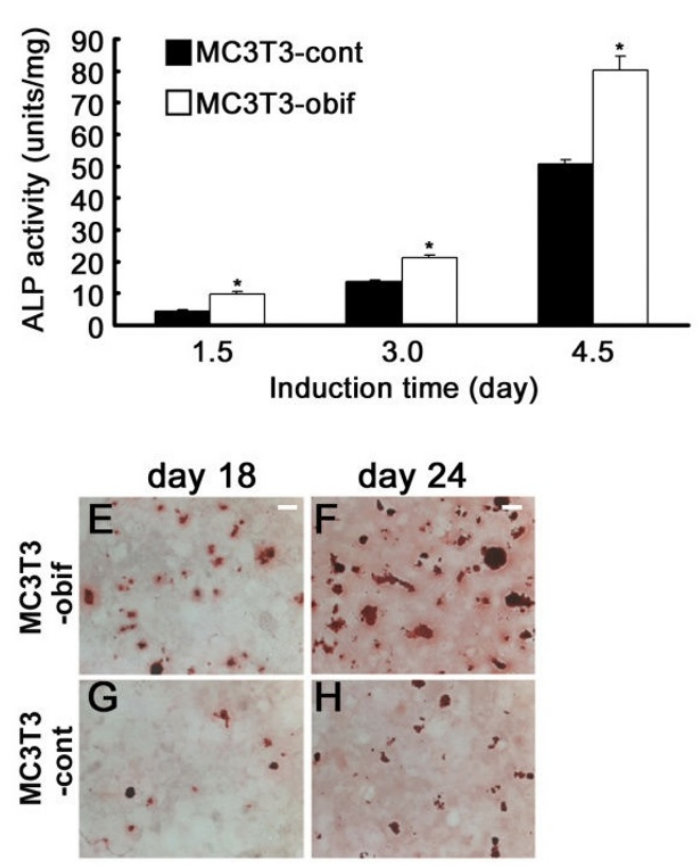

M

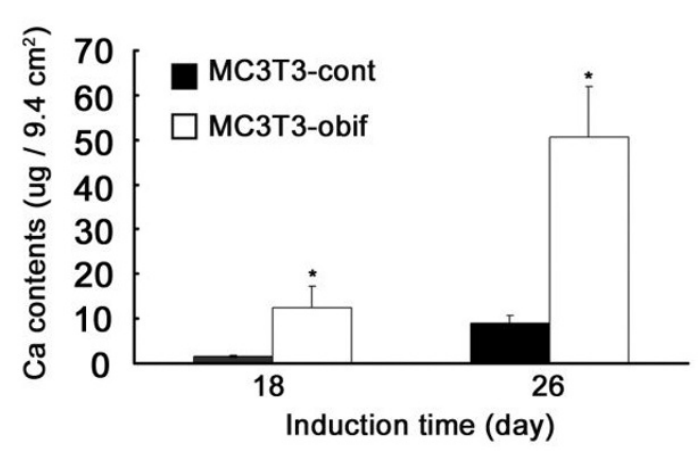

B

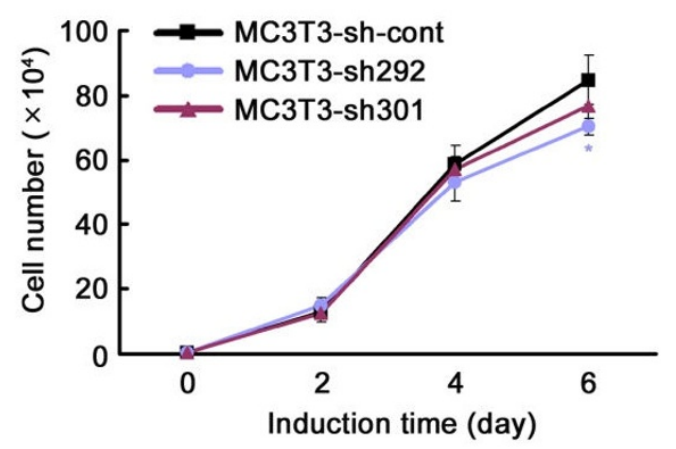

D
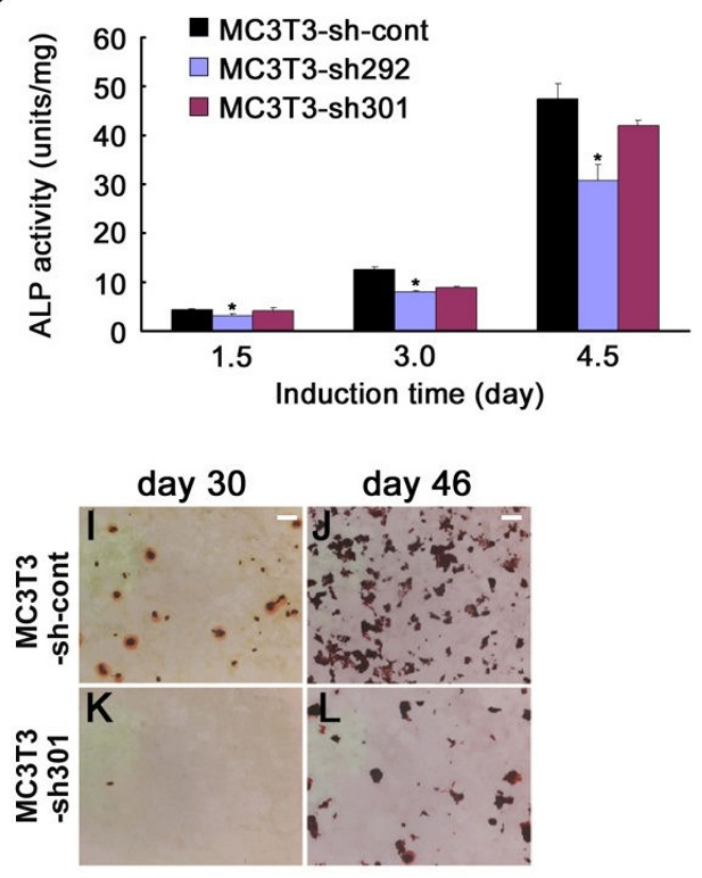

N

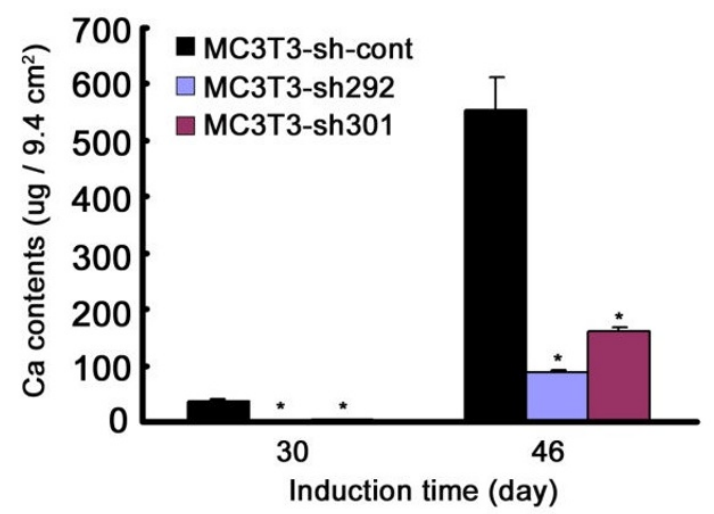

Figure 4 (see legend on next page) 
Figure 4 (see previous page)

The role of obif in the osteoblastic differentiation of MC3T3-E I cells. (A, B) Effect of obif expression on cell growth in the MC3T3-EI cells. The proliferation rate decreased somewhat in MC3T3-obif compared with MC3T3-cont (A). Cells infected with retroviruses expressing shRNA against obif (MC3T3-sh292, MC3T3-sh30I) showed almost the same level of cell growth with MC3T3-sh-cont (B). (C) Effect of obif expression on ALP activity in MC3T3-EI cells cultured in the presence of ascorbic acid and $\beta$-glycerophosphate. (D) Effect of expression of shRNAs against obif in MC3T3-EI cells. The reduction of obif expression caused a significant decrease of ALP activity at all time points. The decrease was proportionate to the strength of the shRNA's knockdown effects. (E-N) Mineral deposition visualized by Alizarin Red staining (E-L), and calcium contents measured by a colorimetric assay (M, N). The mineral deposition observed in MC3T3-obif cells and MC3T3-cont cells at days 18 and $24(\mathrm{E}-\mathrm{H})$. The mineral deposition observed in MC3T3-sh30I cells compared to MC3T3-sh-cont cells at days 30 and 46 (IL). Scale bars $=2 \mathrm{~mm}$. Calcium contents were significantly higher in MC3T3-obif cells than in MC3T3-cont cells both at day 18 and day 26 (M). Calcium deposition in MC3T3-sh292/30I and MC3T3-sh-cont cells at days 30 and 46 (N).

Runx2 was not affected in MC3T3-sh292 cells at day 8. These results concur with a previous report that suggests obif is a downstream gene of Runx2 [21]. Furthermore, obif promoters contain a number of putative Runx2 binding sites in multiple species (Additional file 5). Next, we examined ocn mRNA levels in obif knocked down cells (Figure 5D). At day 14 and 28, ocn was down-regulated in both MC3T3-sh292 and -sh301 cell. At day 42, the ocn mRNA level in MC3T3-sh301 cells is almost the same as that in the control cells whereas it is significantly lower in MC3T3-sh292 cells. In primary culture cells, ocn mRNA was down-regulated in obif knocked-down cells (Figure $5 \mathrm{E})$.

\section{Extracellular domain of obif can promote osteoblastic differentiation}

Obif protein is a single pass transmembrane protein that localizes to the plasma membranes. In order to investigate the mechanism of obif function, we made two more retroviral constructs. One expresses the N-terminal extracellular domain (ECD), and the other expresses both the ECD and the transmembrane domain (TM) (Figure 6A). Using retroviruses derived from these constructs, we established cells stably expressing partial obif proteins. Both bands of the partial proteins detected by Western blot were larger than their predicted sizes (Figure 6B). Immunocytochemistry analyses using an anti-FLAG antibody showed different subcellular localizations of these genes (Figures $1 \mathrm{~F}$, 6C, and 6D). Proteins including the TM localized to the plasma membranes whereas a large amount of obif-ECD protein localized to the cytoplasm.

Then, we examined the effects of partial obif proteins on the induction of ALP activity and matrix mineralization. MC3T3-ECD and -ECD+TM cells showed strong ALP activities similar to MC3T3-obif cells at all points examined (Figure 6E). Partial obif proteins also stimulated mineralization at days 28 and 42 (Figure 6F). Similar results were observed in experiments using retroviruses expressing partial proteins of human OBIF (Additional file 6).
Next, we generated an obif-fusion protein, consisting of the obif extracellular domain fused to an AP tag. Bands of predicted sizes were detected in lysates from transfected cells by Western blotting using an anti-AP antibody (Figure 6G). On the other hand, in supernatants from transfected cells, bands of larger sizes were detected. When tested for binding to tissue sections and cultured cells, APobif (ECD) bound to bone tissues and differentiating MC3T3-E1 cells (Figures 6I, K, and data not shown). In contrast, the control AP protein did not bind at detectable levels (Figures $6 \mathrm{H}$ and $6 \mathrm{~J}$ ).

\section{Discussion}

We have isolated and functionally characterized a novel plasma membrane protein, obif. Obif is highly expressed in early and late stage osteoblasts of developing mouse embryos, and its transcripts increase during osteoblastic differentiation in several skeletal cell lines. In preosteoblastic MC3T3-E1 cells, differentiation, particularly matrix mineralization, is stimulated when obif is overexpressed, and inhibited when obif is knocked down. Furthermore, we showed that the extracellular domain of obif protein can promote MC3T3-E1 differentiation like the fulllength form of obif, suggesting that obif functions in a ligand-like manner.

Although obif was originally isolated as a molecule that is up-regulated during ATDC5 cell differentiation, we could not detect clear obif/obif expression in chondrocyte-lineage cells in mouse skeletal tissues. This seems due to obif up-regulation by cells surrounding the cartilage nodules during ATDC5 differentiation.

Osteoblastogenesis is a multistep process temporally controlled by transcription factors and secreted growth factors. The centerpiece of the transcriptional control of osteoblast differentiation is the Runx2-dependent pathway. Runx2-deficient mice have a cartilaginous skeleton without any osteoblasts, as osteoblast differentiation is arrested as early as E12.5 [6]. Osterix, a zinc finger-containing protein that is known to be downstream of Runx2, 


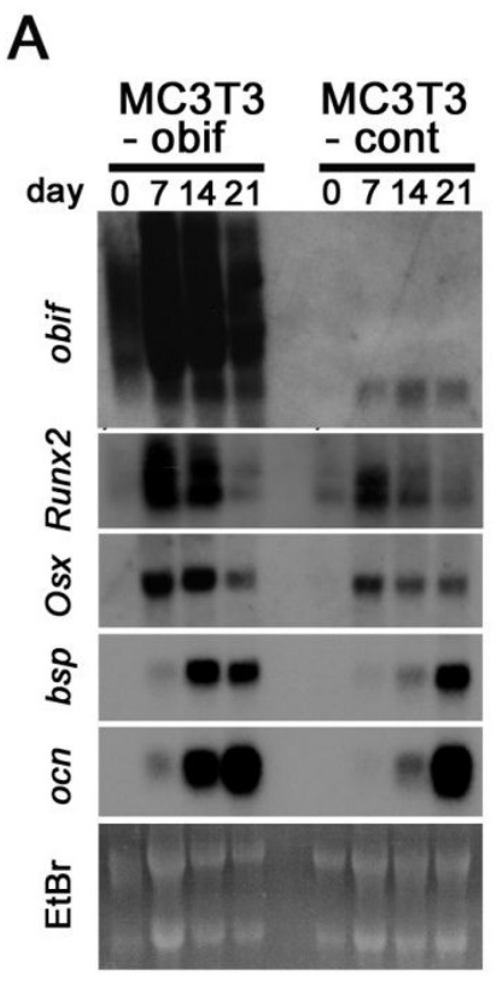

B

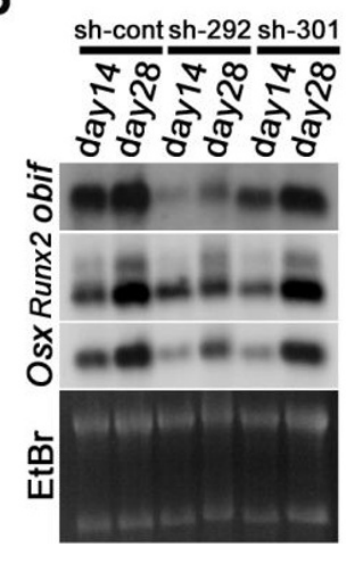

D

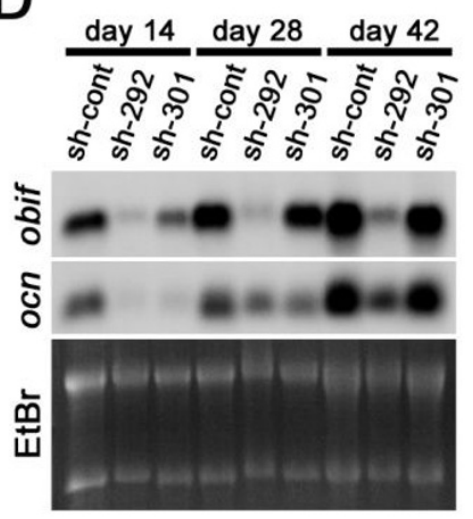

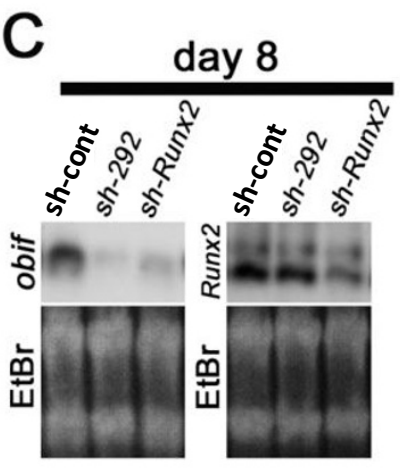

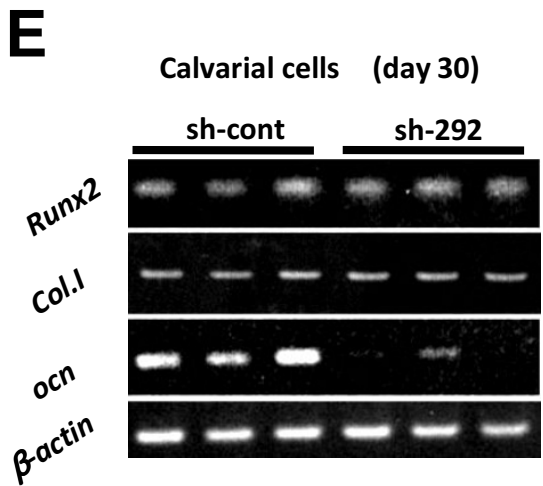

\section{Figure 5}

The effect of obif expression on osteoblastic markers. (A-D) Northern blot analyses of osteoblastic differentiation markers in MC3T3-EI cells. Comparison between MC3T3-obif cells and MC3T3-control cells (A). The overexpression of obif was confirmed in MC3T3-obif cells. Since the coding sequence of obif is connected with an IRES sequence in the retrovirus construct, transcripts produced are longer than endogenous obif transcripts. The mRNA levels of osteoblastic differentiation markers, in particular bsp and ocn increased in MC3T3-obif cells. The comparison among control cells (MC3T3-sh I47) and obif knocked down cells (MC3T3-sh292, -sh30I) (B-D). At day 14, Osx transcripts decreased in obif knocked down cells whereas Runx2 transcripts were not influenced by obif level (B). At day 28, Runx2 was down-regulated in MC3T3-sh292 cells where we could detect only faint levels of obif mRNA. In MC3T3-shRunx2 cells, obif was down-regulated whereas Runx2 was not affected in MC3T3-sh292 cells at day 8 (C). At day 14 and 28, ocn were down-regulated in both MC3T3-sh292 and -sh30I cells (D). At day 42, ocn mRNA level in MC3T3-sh30I cells is almost the same as that in the control cells, but significantly lower in MC3T3sh292 cells. (E) Semi-quantitative RT-PCR of osteoblastic differentiation markers in primary calvarial cells. The data presented are derived from three independent experiments.

is expressed in osteoblast progenitors, and mice without Osterix also lack mature osteoblasts [7]. Although other transcription factors, Dlx5/6, Msx1/2, AP-1 families, twist, and ATF4, have been reported to be involved in osteoblastic differentiation, exact roles of these factors and their relationship with Runx2 remain to be elucidated [22-27]. A recent report suggests that obif (tmem119) is one of the molecules downstream of Runx2 [21]. Our results are con- sistent with this report. However, obif expression is observed as early as Runx2 expression in developing limb buds and during the differentiation of MC3T3-E1 cells. Therefore, the genetic and cell biological relationships between obif and Runx2 will need future studies, including analysis of obif and Runx2 mutant mice. 
A
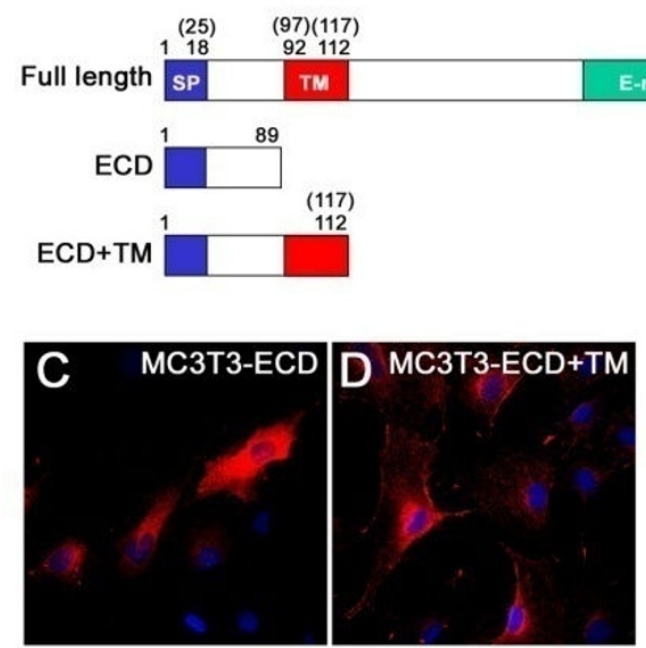

E
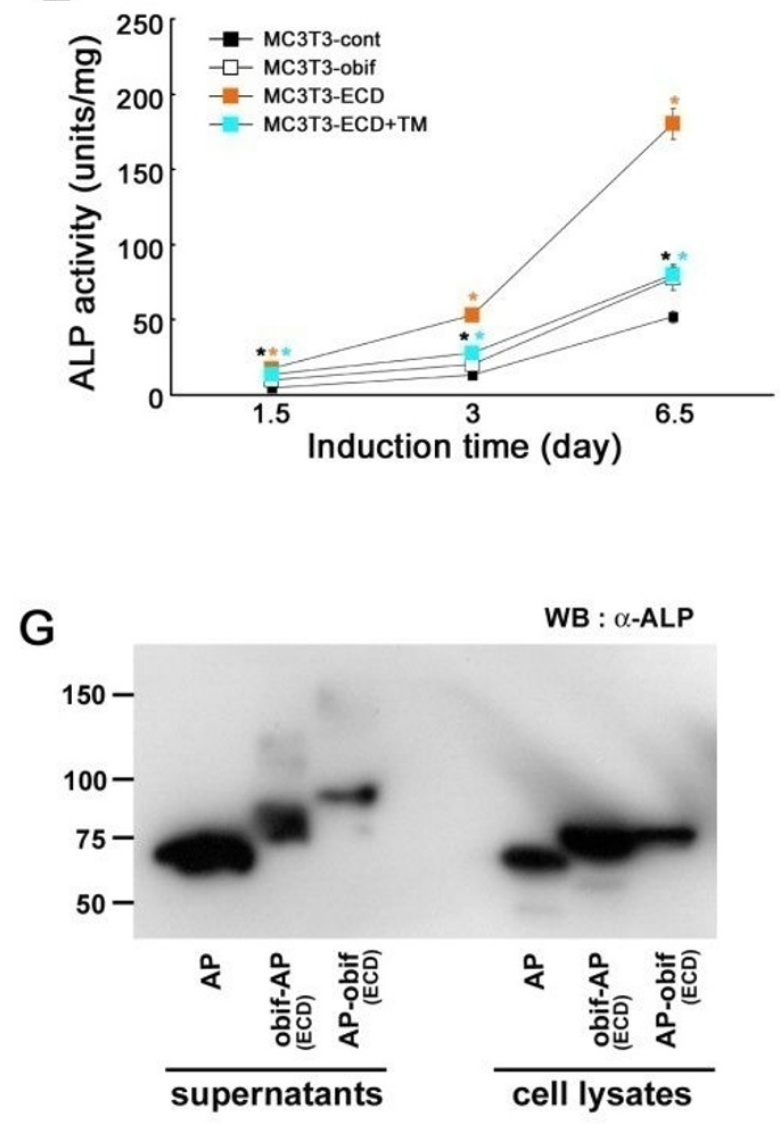

B
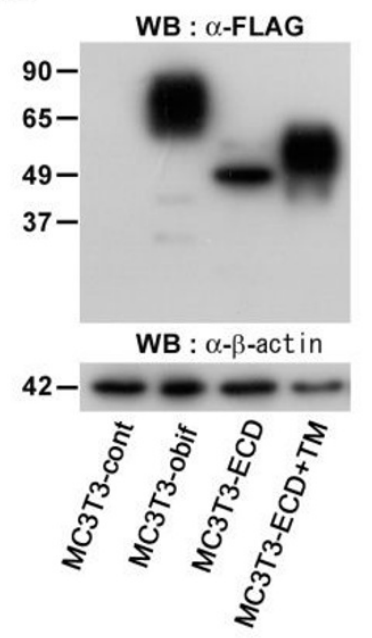

$\mathrm{F}$
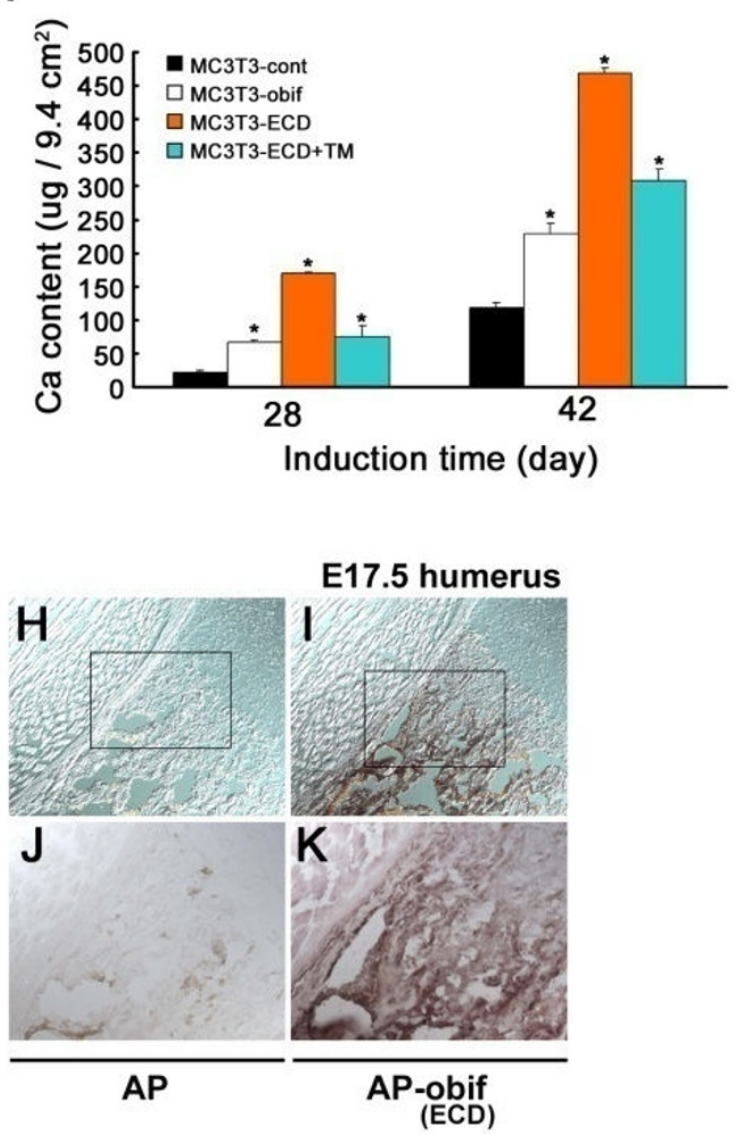

Figure 6 (see legend on next page) 
Figure 6 (see previous page)

Extracellular domain of obif can promote osteoblast differentiation. (A) Schematic representation of partial obif proteins overexpressed in MC3T3-EI cells. Upper: the full-length obif protein, middle: the partial obif fragment containing the Nterminal extracellular domain (ECD), lower: the partial obif fragment composed of the ECD and the transmembrane domain (TM). Numbers represent amino acid residues of mouse (human) obif proteins. (B-F) MC3T3-El cells infected with retroviruses were cultured in the differentiation medium and used for assays. Both of bands of partial obif poteins detected by Western blot were larger than predicted sizes (B). Immunocytochemistry analyses using anti-FLAG antibody (C-D). MC3T3ECD+TM protein localizes to the plasma membranes whereas a large amount of obif-ECD protein localizes to the cytoplasm. Scale bars $=50 \mu \mathrm{m}$. MC3T3-EI cells infected with retroviruses expressing a full-length obif or its partial proteins showed elevated ALP activities at all time points examined (E). Infection with retroviruses expressing full-length and partial proteins significantly promoted mineral deposition both at day 28 and 42 (F). (G) AP fusion proteins (obif-ECD-AP, AP-obif-ECD) and AP protein were detected by Western blotting analysis using anti-AP antibody. Fusion proteins in supernatants are larger than those in lysates from transfected cells. (H-I) AP-obif (ECD) bound to bone tissues whereas control AP protein did not bind at detectable levels. (J, K) Higher magnifications of the squares in $H \& l$, respectively. Scale bars $=100 \mu \mathrm{m}$.

In mouse embryos, cells expressing obif are observed in the periosteum, bone collars, and trabecular bones. The expression pattern of obif suggests that obif functions in osteoblastic development. In the multiple cell line models we used, endogenous obif is markedly upregulated during osteoblastic differentiation. These expression patterns strongly suggest that obif functions in osteoblastogenesis. In committed preosteoblastic MC3T3-E1 cells, obif exerts critical roles both in ALP induction and in matrix mineralization. In obif overexpression and knockdown experiments, cell proliferation is mildly affected but the effect of obif expression levels on differentiation is more significant. Thus we propose that obif may play a role in both proliferation and differentiation, but the primary effect of obif is on differentiation. When obif is knocked down in MC3T3-E1 cells, mRNA levels of Osx and ocn decrease proportionally to the obif transcripts, although Runx2 is not significantly affected. And in a similar experiment using primary calvarial cells, the level of ocn transcript decreases in cells in which obif was knocked down. These results suggest that obif protein is involved in the late differentiation of osteoblast-lineage cells.

Partial proteins including the ECD of both human and mouse obif stimulated osteoblastic differentiation in MC3T3-E1 cells as well as the full-length obif protein. These results suggest that the ECD is sufficient to stimulate osteoblastic differentiation, and the physiological function of obif is mediated by cell-cell or cell-matrix interaction as a ligand. The binding activity of AP-obif (ECD) to bone tissues and differentiating MC3T3-E1 cells supports the hypothesis that an obif receptor-like molecule exists in bone tissues and that obif functions as a ligand. Further investigation of the functional mechanisms of obif may shed light on a new signaling mechanism in osteoblast and chondrocyte differentiation.

\section{Conclusions}

We have isolated and functionally characterized a novel plasma membrane protein, obif. Obif is highly expressed in early and late stage osteoblasts of developing mouse embryos, and its transcripts increase during osteoblastic differentiation in several skeletal cell lines. In preosteoblastic MC3T3-E1 cells, differentiation, particularly matrix mineralization, is stimulated when obif is overexpressed, and inhibited when obif is knocked down. Furthermore, we showed that the extracellular domain of obif protein can promote MC3T3-E1 differentiation like the fulllength form of obif, suggesting that obif functions in a ligand-like manner.

\section{Methods \\ Reagents}

Cell culture medium, $\alpha$-modified minimum essential medium ( $\alpha$-MEM), Dulbecco's modified Eagle's medium (DMEM), a 1:1 mixture of DMEM and Ham's F-12 medium, ascorbic acid, $\beta$-glycerophosphate, and ITS Liquid Media Supplement were purchased from Sigma. Fetal bovine serum (FBS) was purchased from JRH Bioscience (Nichirei, Japan). The following primary antibodies were used: anti-FLAG M2 (Sigma), anti- $\beta$-actin clone AC-74 (Sigma), anti-collagen type I (Santa Cruz). Wnt3a-conditioned medium was kindly provided by Dr. Shin Yonehara (Kyoto University). Recombinant human BMP2 was provided by Osteopharma Inc. (Osaka). Obif siRNA (Stealth $^{\mathrm{TM}}$ RNAs) duplexes were chemically synthesized by Invitrogen. The obif siRNA sequences were as follows: siRNA-1, GCUCGCUGACCUUCCUCAUCAUGUU; SIRNA-2, UCGCUGACCUUCCUCAUCAUGUUCA; siRNA-3, CCUUCCUCAUCAUGUUCAUAGUCUG.

\section{Anti-obif antibody production}

By using PCR, a cDNA encoding a C-terminal portion of mouse obif (residues 113-280; obif-C) was amplified and subcloned into pGEX4T-1 (Amersham Biosciences). The fusion was expressed in Escherichia coli strain DH5 $\alpha$ and 
purified with glutathione Sepharose 4B (Amersham Biosciences) according to the manufacturer's instructions. An antibody against obif was obtained by immunizing rabbits with the purified GST-obif-C (MBL, Japan). The rabbit antisera against obif-C was pre-absorbed with GST-Sepharose and affinity purified with an immunizing fusion protein-bound Sepharose column.

\section{Cell culture}

ATDC5, MC3T3-E1, ST2, and C2C12 cells were obtained from the RIKEN Cell Bank (Ibaraki, Japan). The ATDC5 cells were cultured in a maintenance medium of a $1: 1$ mixture of DMEM and Ham's F-12 medium, and 5\% FBS. MC3T3-E1 cells and ST2 cells were cultured in $\alpha$-MEM supplemented with $10 \%$ FBS. C2C12 cells were cultured in DMEM containing 10\% FBS. Primary mouse calvarial cells were dissected from 2-day old pups. Calvarial cells were isolated by four sequential 15-minute digestions in collagenase/dispase solution (Roche 269638) at $37^{\circ} \mathrm{C}$. Fractions 2-4 were collected, resuspended in media and plated. Freshly harvested cells of less than 4 passages were used for all experiments.

\section{Microarray gene expression profiles}

RNA was harvested and purified with Trizol according to manufacturer's protocol (Invitrogen). Preparation of cRNA and hybridization of probe arrays were performed according to the protocols of the manufacturer using the GeneChip Mouse Genome 4302.0 Array (Affymetrix, Santa Clara, CA).

\section{Production of recombinant retrovirus and infection}

The retroviral vector expressing mouse or human obif was constructed in the pBMN-I-GFP vector that was kindly provided by Dr. Gary Nolan (Stanford University). In brief, the full- or partial-length coding regions of mouse or human obif cDNA that were added to the FLAG tag at the $\mathrm{C}$-terminus were inserted into the multicloning site of pBMN-I-GFP. PCR were performed using FANTOM clone [28] cDNA (\#BC025600) or cDNA produced from Human Fetal Brain Total RNA (purchased from Clontech). Reduction of obif expression was achieved through the retroviral infection of cells with short hairpin RNAs directed against the obif mRNA, using pSUPER.retro.neo+GFP (pSUP) plasmids (Oligoengine). 19nt target sequences were selected in the mouse obif and Runx2 cDNA coding sequences as follows: obif sh292, 5'CGCTGACCTTCCTCATCAT-3' (292-310); obif sh301, 5'TCCTCATCATGTTCATAGT-3' (301-319); Runx2, 5'CCACTTACCACAGAGCTAT-3' (857-875). Each one was used to design a 60-nt oligo, which was subcloned between the BglII and HindIII restriction sites of the pSUP vector according to the manufacturer's instructions. As a control, the same set of experiments was performed using an irrelevant sequence (Dharmacon Research). To pro- duce the retroviral particles, the plasmid DNA was transfected along with a helper plasmid into a subline of the $293 \mathrm{~T}$ cell line; supernatant was collected every day starting at $24 \mathrm{hr}$ posttransfection for 3 days. For infection, cells plated at low density were incubated in virus-conditioned medium for $1-2$ days in the presence of $8 \mu \mathrm{g} / \mathrm{ml}$ polybrene. Virus-conditioned medium was used in a 1:1 dilution with normal growth medium. In the case of infection with retroviruses expressing shRNA, infected cells were selected based on their resistance to G418.

\section{Western blot analysis}

Cells were harvested in lysis buffer $(50 \mathrm{mM}$ Tris-HCL [pH7.5], $0.15 \mathrm{M} \mathrm{NaCl}$, containing 1\% NP-40, $1 \mu \mathrm{M}$ sodium orthovanadate). After sonication, cell debris was removed by centrifugation, and the supernatants were collected. Equal amounts of total proteins were then prepared for Western blot analysis according to a previously described protocol [29]. The primary antibody dilutions were 1:1000 (anti-FLAG M2), 1:500 (anti-obif), and $1: 5000$ (anti- $\beta$-actin).

\section{Subcellular localization analysis}

Stably infected cells were used for localization analysis according to a previously described protocol [29]. The primary antibodies were used at dilutions of 1:500 (antiFLAG M2) and 1:250 (anti-obif). For nuclear staining, we added 4,6, -diamidino-2-phenylindole dihydrochloride (DAPI, Sigma) at a dilution of 1:1000 in the secondary antibody solution.

\section{Subcellular fractionation}

Cells were harvested in ice-cold buffered sucrose $(0.25 \mathrm{M}$. sucrose-10 mM Tris-HCl buffer [pH 7.5]) and whole-cell lysates prepared by sonication were centrifuged in a swinging bucket rotor at $80 \times \mathrm{g}$ for $5 \mathrm{~min}$ at $4^{\circ} \mathrm{C}$. Then the supernatant was spun at $12,000 \times \mathrm{g}$ for $10 \mathrm{~min}$. The resultant pellet was designated the mitochondrial fraction. The postmitochondrial supernatant was then subjected to centrifugation at $100,000 \times \mathrm{g}$ for $90 \mathrm{~min}$ in a Beckman TLA120.2 rotor at $4{ }^{\circ} \mathrm{C}$. The high-spin pellet was designated the microsomal fraction, and the supernatant was designated the cytoplasmic fraction.

\section{In situ hybridization and Northern blot analysis}

Mouse obif (\#BC025600), Sox9 (\#4933413I11), and collagen1 (\#D930048E22) cDNAs obtained from the RIKEN FANTOM2 collection were used to prepare antisense probes. A $540 \mathrm{bp}$ fragment of mouse collagen 2 and a 520 bp fragment of mouse collagen 10 were obtained by RT-PCR and subcloned into the pGEM-T Easy vectors (Promega). Mouse osteopontin and osteocalcin cDNAs were kindly provided by Dr. Toshihisa Komori (Nagasaki University, Japan). Whole mount in situ hybridization and section in situ hybridization were performed as described 
previously [30]. Northern blot hybridization was performed as described previously [31]. The entire protein coding regions of obif, bsp, a 1-kb fragment of Runx2 cDNA (nucleotides 280-1281), a 0.5-kb fragment of Osterix cDNA (nucleotides 115-611), and a 0.47-kb fragment of ocn cDNA (nucleotides 1-470) were used as radiolabeled probes.

\section{Immunohistochemistry}

We followed the immunostaining procedures described previously [32]. The specimens were observed under a laser confocal microscope (LSM510, Carl Zeiss) or a fluorescent microscope (Axioskop 2 Plus, Carl Zeiss).

\section{Proliferation assay}

Cells were plated at a density of $3 \times 10^{3}$ cells $/ \mathrm{cm}^{2}$ and cultured in growth medium. At each time point, cells were harvested and counted using a haemocytometer. Duplicate measurements were performed on three independent wells for each time point.

\section{Osteoblastic differentiation}

MC3T3-E1 cells, ST2 cells: Cells were plated in 6-well or 12-well plates in triplicate at a density of $2.5 \times 10^{4}$ cells/ $\mathrm{cm}^{2}$ and were cultured in growth medium. One day after the cells reached confluence, they were cultured in differentiation medium ( $\alpha$-MEM containing $50 \mathrm{ug} / \mathrm{ml}$ ascorbic acid and $2 \mathrm{mM} \beta$-glycerophosphate) or Wnt3a- conditioned medium that was used at a 1: 3 dilution with normal growth medium. Determination of ALP activity, Alizarin Red S staining and $\mathrm{Ca}^{2+}$ accumulation was done as described elsewhere [33,34]. C2C12 cells: For BMP2 induction, cells were cultured in medium supplemented with $2.5 \%$ FBS and $300 \mathrm{ng} / \mathrm{ml}$ recombinant human BMP2.

\section{Chondrogenic differentiation}

After ATDC5 cells were plated in 6-well or 12-well plates in triplicate at a density of $2.5 \times 10^{4}$ cells $/ \mathrm{cm}^{2}$, differentiation induction and evaluation of matrix proteoglycan synthesis were performed as described elsewhere [35].

\section{Semi-quantitative RT-PCR}

One $\mu$ g samples of RNA were subjected to reverse transcription with a random hexamer as a primer, and semiquantitative PCR was performed for each gene using the following primers: for mouse runx2, 5'-AAATGCCTCCGCTGTTATGAA (sense primer) and 5'-GCTCCGGCCCACAAATCT (antisense primer); for mouse collagen 1, 5'-CCCAAGGAAAAGAAGCACGTC (sense primer) and 5'-AGGTCAGCTGGATAGCGACATC (antisense primer); for mouse ocn, 5'-CCGGGAGCAGTGTGAGCTTA (sense primer) and 5'-AGGCGGTCTTCAAGCCATACT (antisense primer); and for mouse $\beta$-actin 5'-CGTGCGTGACATCAAAGAGAA (sense) and 5'-TGGATGCCACAGGATTC-
CAT (antisense). PCR conditions were 28 cycles of $94^{\circ} \mathrm{C}$ for $20 \mathrm{sec}, 55^{\circ} \mathrm{C}$ for $30 \mathrm{sec}$, and $72^{\circ} \mathrm{C}$ for $30 \mathrm{sec}$. Post PCR, each sample was subjected to electrophoresis on a $2 \%$ agarose gel and visualized by ethidium bromide staining.

\section{Statistical analysis}

Data were examined for distribution, variance homogeneity (F-test) and analyzed using Student's unpaired $t$-test (2 tailed) for all analyses. P $<0.05$ was considered statistically significant. Unless otherwise specified, all data are presented as mean \pm SEM or mean + SE.

\section{Production of the AP tag-obif fusion protein}

We followed the procedures described previously [36]. Briefly, AP fusion proteins were produced by inserting the extracellular domain of obif into the APtag- 5 vector that was kindly provided by Dr. Mitsuharu Hattori (Nagoya City University). After producing conditioned medium from transiently transfected 293 T cells, we spun out debris and filtered $(0.45-\mu \mathrm{m}$ pore size $)$ the supernatant.

\section{In situ analysis of AP tag-obif binding to tissue sections}

We washed the sections in HBS and in HBAH buffer. AP fusion proteins were added and incubated at room temperature for $90 \mathrm{~min}$. After a $15 \mathrm{~min}$ incubation in preheated HBS, in a $65^{\circ}$ water bath, BCIP/NBT substrate was added.

\section{Competing interests}

The authors declare that they have no competing interests.

\section{Authors' contributions}

TK and TF designed the project. TK carried out the molecular, cell biological and immunohistochemical studies. KM and KT participated in the cell biological study. TM and TK carried out microarray analysis. TK and TF wrote the manuscript. HY and TF supervised the project.

\section{Additional material}

\section{Additional file 1}

obif is conserved among species. The deduced amino acid sequences of chicken, mouse, rat, and human obif proteins. GenBank accession numbers for the sequences are chicken, XP 415183.1; mouse, BK006092; rat, NP 001100625.1; human, AAQ88755.1. All of them contain the $N$-terminal signal peptide, a single transmembrane domain, and a glutamic acid-rich region (E-rich). Black boxes indicate potential O-glycosylation sites conserved among species.

Click here for file

[http://www.biomedcentral.com/content/supplementary/1471213X-9-70-S1.PDF] 


\section{Additional file 2}

Verification of overexpression of obif protein by immunostaining. MC3T3-E1 and ATDC5 cells were infected with retroviruses expressing both obif and GFP (MC3T3-obif) (A-C), (ATDC5-obif) (G-I) or expressing GFP only (MC3T3-cont) (D-F), (ATDC5-cont) (J-L), Cells were stained with anti-obif antibody (red) and nuclei were stained with DAPI (blue) $(C, F, I, L)$.

Click here for file

[http://www.biomedcentral.com/content/supplementary/1471213X-9-70-S2.PDF]

\section{Additional file 3}

Verification of knock down of obif protein by Western blot analyses. (Left) Western blot analysis of cell extracts from MC3T3-obif and ATDC5-obif. To knock obif down, each of three siRNAs designed against obif and a negative-control siRNA were transfected into cell lines. Nontransfected cells were also electrophoresed. Blots were probed with antiobif antibody. (Right) Western blot analysis of MC3T3-obif infected with retroviruses expressing control sh-cont, sh301, and sh292. Blots were probed with anti-obif antibody. Sh292 sequence overlaps siRNA-1 and siRNA-2 sequences, and sh301 sequence overlaps siRNA-3 sequence. Suppressive effect of sh292 is significantly stronger than that of sh301. Click here for file

[http://www.biomedcentral.com/content/supplementary/1471213X-9-70-S3.PDF]

\section{Additional file 4}

Calcium contents observed in MC3T3-E1 cells expressing human obif and control cells at days 18 and 26. Calcium contents were significantly higher in MC3T3-hOBIF cells than in MC3T3-cont cells both at day 18 and 26.

Click here for file

[http://www.biomedcentral.com/content/supplementary/1471213X-9-70-S4.PDF]

\section{Additional file 5}

Comparative analysis of obif gene promoter. Schematic illustration of chick, mouse, rat, and human obif promoter. Putative Runx 2 binding sites are indicated by open triangle.

Click here for file

[http://www.biomedcentral.com/content/supplementary/1471213X-9-70-S5.PDF]

\section{Additional file 6}

Retroviruses expressing human OBIF exhibited a similar effect on mineralization of MC3T3-E1 cells as those infected with mouse obif retroviruses. Infection with retroviruses expressing full-length and partial human OBIF significantly promoted mineral deposition at day 33. Click here for file

[http://www.biomedcentral.com/content/supplementary/1471213X-9-70-S6.PDF]

\section{Acknowledgements}

We thank A. Tani, Y. Kawakami, M. Kadowaki, H. Tsujii, K. Sone, and S. Kennedy for technical assistance. We also thank Drs. S. Yonehara, G. Nolan, T. Komori, H. Asahara, M. Hijikata and K. Shimotohno for reagents. This work was supported by Grant-in-Aid for Scientific Research (B), Research for Promoting Technological Seeds, Linking Mechanism of Research Results to Practical Application, the Uehara Science Foundation,
Mochida Memorial Foundation for Medical and Pharmaceutical Research and Takeda Science Foundation.

\section{References}

I. Karsenty G, Wagner EF: Reaching a genetic and molecular understanding of skeletal development. Dev Cell 2002, 2:389-406.

2. Zelzer $E$, Olsen $B R$ : The genetic basis for skeletal diseases. Nature 2003, 423:343-8.

3. Hartmann C: A Wnt canon orchestrating osteoblastogenesis. Trends Cell Biol 2006, 16:15I-8.

4. Otto F, Thornell AP, Crompton T, Denzel A, Gilmour KC, Rosewell IR, Stamp GW, Beddington RS, Mundlos S, Olsen BR, Selby PB, Owen MJ: Cbfal, a candidate gene for cleidocranial dysplasia syndrome, is essential for osteoblast differentiation and bone development. Cell 1997, 89:765-7|

5. Ducy P, Zhang R, Geoffroy V, Ridall AL, Karsenty G: Osf2/Cbfa I: a transcriptional activator of osteoblast differentiation. Cell 1997, 89:747-54.

6. Komori T, Yagi H, Nomura S, Yamaguchi A, Sasaki K, Deguchi K, Shimizu Y, Bronson RT, Gao YH, Inada M, Sato M, Okamoto R, Kitamura $Y$, Yoshiki S, Kishimoto $\mathrm{T}$ : Targeted disruption of Cbfal results in a complete lack of bone formation owing to maturational arrest of osteoblasts. Cell 1997, 89:755-64.

7. Nakashima K, Zhou X, Kunkel G, Zhang Z, Deng JM, Behringer RR, de Crombrugghe $B$ : The novel zinc finger-containing transcription factor osterix is required for osteoblast differentiation and bone formation. Cell 2002, 108: 17-29.

8. Rodda SJ, McMahon AP: Distinct roles for Hedgehog and canonical Wnt signaling in specification, differentiation and maintenance of osteoblast progenitors. Development 2006, 133:323|-44.

9. Day TF, Guo X, Garrett-Beal L, Yang Y: Wnt/beta-catenin signaling in mesenchymal progenitors controls osteoblast and chondrocyte differentiation during vertebrate skeletogenesis. Dev Cell 2005, 8:739-50.

10. Hill TP, Spater D, Taketo MM, Birchmeier W, Hartmann C: Canonical Wnt/beta-catenin signaling prevents osteoblasts from differentiating into chondrocytes. Dev Cell 2005, 8:727-38.

II. Koziel L, Kunath M, Kelly OG, Vortkamp A: ExtI-dependent heparan sulfate regulates the range of Ihh signaling during endochondral ossification. Dev Cell 2004, 6:80I-13.

12. Zhou G, Zheng Q, Engin F, Munivez E, Chen Y, Sebald E, Krakow D, Lee B: Dominance of SOX9 function over RUNX2 during skeletogenesis. Proc Natl Acad Sci USA 2006, 103:1 9004-9.

13. Akiyama H, Chaboissier MC, Martin JF, Schedl A, de Crombrugghe B: The transcription factor Sox 9 has essential roles in successive steps of the chondrocyte differentiation pathway and is required for expression of Sox5 and Sox6. Genes Dev 2002, 16:2813-28.

14. Akiyama H, Lyons JP, Mori-Akiyama Y, Yang X, Zhang R, Zhang Z, Deng JM, Taketo MM, Nakamura T, Behringer RR, et al: Interactions between Sox 9 and beta-catenin control chondrocyte differentiation. Genes Dev 2004, I 8: 1072-87.

15. Julenius K, Molgaard A, Gupta R, Brunak S: Prediction, conservation analysis, and structural characterization of mammalian mucin-type O-glycosylation sites. Glycobiology 2005, I 5: 153-64.

16. Katagiri T, Yamaguchi A, Komaki M, Abe E, Takahashi N, Ikeda T, Rosen V, Wozney JM, Fujisawa-Sehara A, Suda T: Bone morphogenetic protein-2 converts the differentiation pathway of C2CI 2 myoblasts into the osteoblast lineage. J Cell Biol 1994 127:1755-66.

17. Otsuka E, Yamaguchi A, Hirose S, Hagiwara H: Characterization of osteoblastic differentiation of stromal cell line ST2 that is induced by ascorbic acid. Am J Physiol 1999, 277: CI32-8.

18. Atsumi T, Miwa Y, Kimata K, lkawa Y: A chondrogenic cell line derived from a differentiating culture of AT805 teratocarcinoma cells. Cell Differ Dev 1990, 30:109-16.

19. Sudo H, Kodama HA, Amagai Y, Yamamoto S, Kasai S: In vitro differentiation and calcification in a new clonal osteogenic cell line derived from newborn mouse calvaria. J Cell Biol 1983 , 96: $191-8$.

20. Tu X, Joeng KS, Nakayama KI, Nakayama K, Rajagopal J, Carroll TJ, McMahon AP, Long F: Noncanonical Wnt signaling through G 
protein-linked PKCdelta activation promotes bone formation. Dev Cell 2007, I 2: I I3-27.

21. Hecht J, Seitz V, Urban M, Wagner F, Robinson PN, Stiege A, Dieterich C, Kornak U, Wilkening U, Brieske N, Zwingman C, Kidess A, Stricker S, Mundlos S: Detection of novel skeletogenesis target genes by comprehensive analysis of a Runx2(-I-) mouse model. Gene Expr Patterns 2007, 7:102-12.

22. Acampora D, Merlo GR, Paleari L, Zerega B, Postiglione MP, Mantero S, Bober E, Barbieri O, Simeone A, Levi G: Craniofacial, vestibular and bone defects in mice lacking the Distal-less-related gene DIx5. Development 1999, 1 26:3795-809.

23. Bialek P, Kern B, Yang X, Schrock M, Sosic D, Hong N, Wu H, Yu K, Ornitz DM, Olson EN, Justice MJ, Karsenty G: A twist code determines the onset of osteoblast differentiation. Dev Cell 2004, 6:423-35.

24. Jochum W, David JP, Elliott C, Wutz A, Plenk H Jr, Matsuo K, Wagner EF: Increased bone formation and osteosclerosis in mice overexpressing the transcription factor Fra-I. Nat Med 2000, 6:980-4.

25. Sabatakos G, Sims NA, Chen J, Aoki K, Kelz MB, Amling M, Bouali Y, Mukhopadhyay K, Ford K, Nestler EJ, Baron R: Overexpression of DeltaFosB transcription factor(s) increases bone formation and inhibits adipogenesis. Nat Med 2000, 6:985-90.

26. Satokata I, Ma L, Ohshima H, Bei M, Woo I, Nishizawa K, Maeda T, Takano Y, Uchiyama M, Heaney S, Peters H, Tang Z, Maxson R, Maas $\mathrm{R}$ : Msx2 deficiency in mice causes pleiotropic defects in bone growth and ectodermal organ formation. Nat Genet 2000, 24:391-5.

27. Yang X, Matsuda K, Bialek P, Jacquot S, Masuoka HC, Schinke T, Li L, Brancorsini S, Sassone-Corsi P, Townes TM, Hanauer A, Karsenty G: ATF4 is a substrate of RSK2 and an essential regulator of osteoblast biology; implication for Coffin-Lowry Syndrome. Cell 2004, I 1 7:387-98.

28. Osato N, Itoh M, Konno H, Kondo S, Shibata K, Carninci P, Shiraki T, Shinagawa A, Arakawa T, Kikuchi S, Sato K, Kawai J, Hayashizaki Y: A computer-based method of selecting clones for a full-length cDNA project: simultaneous collection of negligibly redundant and variant cDNAs. Genome Res 2002, I 2:1 I 27-34.

29. Inoue $T$, Terada $K$, Furukawa $A$, Koike $C$, Tamaki $Y$, Araie M, Furukawa $\mathrm{T}$ : Cloning and characterization of $\mathrm{mr}-\mathrm{s}$, a novel SAM domain protein, predominantly expressed in retinal photoreceptor cells. BMC Dev Biol 2006, 6:15.

30. Riddle RD, Johnson RL, Laufer E, Tabin C: Sonic hedgehog mediates the polarizing activity of the ZPA. Cell 1993, 75:I40I-16.

31. Furukawa T, Kozak CA, Cepko CL: rax, a novel paired-type homeobox gene, shows expression in the anterior neural fold and developing retina. Proc Natl Acad Sci USA 1997 94:3088-93.

32. Furukawa A, Koike C, Lippincott P, Cepko CL, Furukawa T: The mouse Crx 5'-upstream transgene sequence directs cell-specific and developmentally regulated expression in retinal photoreceptor cells. J Neurosci 2002, 22:1640-7.

33. Stanford CM, Jacobson PA, Eanes ED, Lembke LA, Midura RJ: Rapidly forming apatitic mineral in an osteoblastic cell line (UMR 106-0 I BSP). J Biol Chem 1995, 270:9420-8.

34. Hinoi E, Fujimori S, Wang L, Hojo H, Uno K, Yoneda Y: Nrf2 negatively regulates osteoblast differentiation via interfering with Runx2-dependent transcriptional activation. J Biol Chem 2006, 28 I: $18015-24$.

35. Gori F, Demay MB: BIG-3, a novel WD-40 repeat protein, is expressed in the developing growth plate and accelerates chondrocyte differentiation in vitro. Endocrinology 2004, 145:1050-4.

36. Flanagan JG, Cheng HJ, Feldheim DA, Hattori M, Lu Q, Vanderhaeghen P: Alkaline phosphatase fusions of ligands or receptors as in situ probes for staining of cells, tissues, and embryos. Methods Enzymol 2000, 327:19-35.

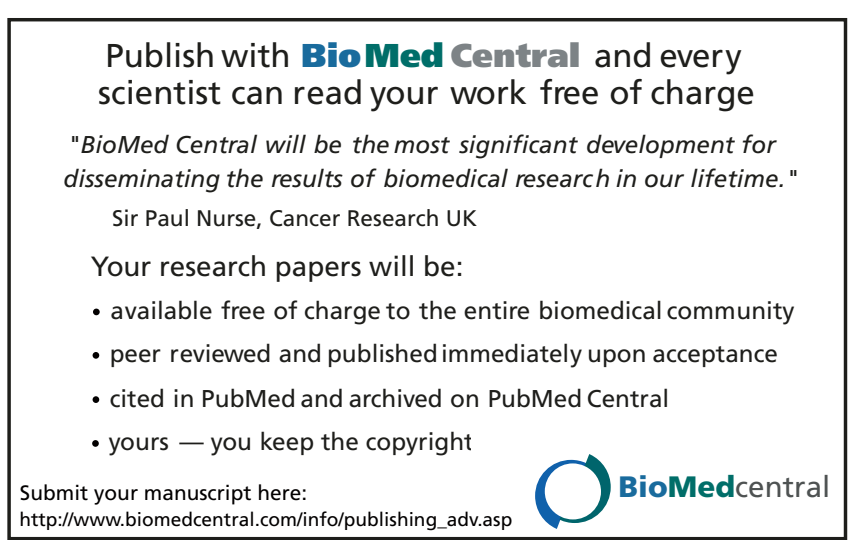

